\title{
Moringa oleifera Seeds Extracts / Magnetite based Bionanocomposites for Hexavalent Chromium Uptake
}

\author{
Tafadzwa Shekede and ${ }^{1}$ Ajay Kumar Mishra
}

\begin{abstract}
Sequestration of hexavalent chromium six Cr (VI) from wastewater is a big challenge due to its high toxicity and threat to living organisms. In this investigation, highly ordered mesoporous magnetite nano particles functionalised with protein extracts from de-oiled Moringa seeds were synthesised. High-resolution TEM (HRTEM) and Scanning electron microscopy (SEM/EDS) results showed good dispersion of organic compounds on de-oiled Moringa oleifera iron nano particles in water $\left(\mathrm{DMOSFeNP}_{\mathrm{H} 2 \mathrm{O})}\right.$ compared to the other two bionanocomposites i.e. DMOSFeNPsalt and DMOS

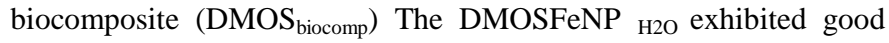
separability in effective removal of $\mathrm{Cr}$ (VI). The capping of the magnetite with Moringa water extracts greatly improved the removal efficiency of $\mathrm{Cr}$ (VI) to $80 \%$ at equilibrium time. The adsorption of $\mathrm{Cr}$ (VI) ions by $\mathrm{DMOSFeNP}_{\mathrm{H} 20}$, DMOSFeNPsalt and $\mathrm{DMOS}_{\text {biocomp }}$ followed Fraundlich and Langmuir adsorption isotherm model with $\mathrm{R}^{2}$ values of $0.94,0.77$ and 0.67 respectively. The Pearson's correlation coefficient showed that the adsorption process was $1^{\text {st }}$ order kinetics for DMOSFeNP $\mathrm{H}_{2 \mathrm{O}}$ and $2^{\text {nd }}$ order for DMOSFeNP salt and $\mathrm{DMSO}_{\text {biocomp }}$ indicating chemisorption and physio-sorption reactions. In this investigation, the functionalization was done using crude salt and water extracts from Moringa Oleifera seeds, and this of its kind in adsorption of $\mathrm{Cr}$ (VI) in aqueous solution.
\end{abstract}

Index Terms - Cr (VI), Magnetite, Bionanocomposite; Moringa oleifera, Adsorption isotherms; Kinetic models.

\section{INTRODUCTION}

Hexavalent chromium has been recognised as one of the major toxic substances by United States Environmental Protection Agency (USEPA), because of its carcinogenic effects and recommended limits in drinking water is $0,05-1 \mathrm{mg} / \mathrm{L}$. [1]. Chromium generally exists as non-toxic and immobile trivalent (Cr (III) and hexavalent (Cr (VI) which is readily soluble in water. [2]. Generally, Cr containing effluents contaminate the environment at their point of disposal where $\mathrm{Cr}$ (III) undergoes oxidation and forms $\mathrm{Cr}$ (VI). In acidic medium, hexavalent chromium exists as a tetraoxohydrochromate $\left(\mathrm{HCrO}_{4}{ }^{-}\right)$and dichromate $\left(\mathrm{Cr}_{2} \mathrm{O}_{7}{ }^{2-}\right)$ species and at alkaline $\mathrm{pH}$, it is present as a tetraoxochromte $\left(\mathrm{CrO}_{4}^{2-}\right)$ in solution. Hexavalent chromium is more mobile while the trivalent form is less toxic and strongly retained in the soil. However, it is probable for the trivalent chromium to be oxidized to the hexavalent state due to

Tafadzwa Shekede, Student, University of Johannesburg, Johannesburg, South Africa .

Ajay Kumar Mishra, University of Johannesburg, South Africa. the manganese oxides in the soil. [3]. Treatment of chromium (VI) can be done using various techniques, which involves chemical, physical and biological processes. In recent years, use of low costs adsorbents have been considered to reduce the $\mathrm{Cr}$ concentration in tannery effluents. Adsorption could be a good alternative technology for the removal of heavy metals, especially at low concentration. The adsorbents may be of organic or biological origin, modified materials, nano sized materials, industrial by-products or mineral substance, modified bio-polymers, biomass bio-adsorbents, modified agricultural waste and biological waste [4].

Nano crystalline and metal oxides have attracted international interest from researchers over the years due to their unusual physical and surface chemical and catalytic properties, cost effective, biodegradability and environmentally friendly nature. Among the metal oxide nanoparticles, iron oxide magnetic nanoparticles are of great interest to many scientists in recent years because of their small size, good stability, low cost, high magnetic permeability and large surface for unique physio-chemical properties. Isolated nanoparticles exhibit amazing properties and when mixed with other materials, the resultant compound attains improved properties because of the increased surface to volume ratio. Fe ions may be used to catalyze Fenton-like reactions for the generation of hydroxyl radicals using strong oxidizing agents as precursors. Hydroxyl radicals have high oxidation potential and can degrade organic molecules such as dyes generated in textile effluents [5]. There are many plant based bionanocomposite materials available on the market.

The aim of this study was to evaluate the effectiveness of using De-oiled Moringa oleifera seeds extracts modified bionanocomposites to remove $\mathrm{Cr}$ (VI) ions from waste solution. The overall goal was to increase surface area of adsorption and capitalize on the magnetic properties of the bionanocomposites for ease regeneration of the biosorbent.

\section{MATERIALS AND METHOD}

\section{A. Materials}

Moringa oleifera seeds was obtained from Limpopo province, Republic of South-Africa. Stock standards for Cr (VI) were prepared by diluting pure standard solutions of the potassium dichromate $\left(\mathrm{K}_{2} \mathrm{Cr}_{2} \mathrm{O}_{7}\right)$ in distilled water. The 1000-ppm standard solution of $\mathrm{K}_{2} \mathrm{Cr}_{2} \mathrm{O}_{7}$ were sourced from Associated Chemical Enterprises (Pvt), South Africa. Hydrated 
iron chloride $\left(\mathrm{FeCl}_{2} / \mathrm{FeCl}_{3}\right)$ were purchased from Merck, Darmstadt Germany. All other reagents were of analytical grade and used without further treatment. Deionised water was prepared by a Milli-Q system.

\section{B. Preparation of de-oiled Moringa oleifera seeds}

The $350 \mu \mathrm{m}$-crushed seeds were heated for $24 \mathrm{hrs}$ in a Soxhlet apparatus using normal hexane to remove the oil before drying at $50{ }^{\circ} \mathrm{C}$ to a constant dry weight in an oven.

\section{Preparation of the de-oiled Moringa oleifera seed bio-composite}

The de-oiled Moringa oleifera coated magnetite bio-composite was synthesised by co-precipitation technique. Fifty grams de-oiled Moringa oleifera seeds were mixed with $1 \mathrm{MFeCl}_{2}$ and $0.5 \mathrm{MFeCl}_{3}$ as precursors in a $500 \mathrm{ml}$ beaker. The dried sample was crushed to powder and sieved through a $350 \mu \mathrm{m}$ sieve for the adsorption experiments.

\section{Synthesis of Moringa oleifera modified magnetite iron oxide nanoparticles through co-precipitation method}

The magnetite iron oxide nano particles were synthesised via co-precipitation methods using the crude extracts solutions from de-oiled Moringa oleifera seeds. Synthetic procedure was done according to procedure by Wang et al. (2011), with some few modifications. The magnetite nanoparticles were washed several times in distilled water before vacuum dried at $50^{\circ} \mathrm{C}$ for $12 \mathrm{hrs}$. After drying, the magnetite nanoparticles were crushed to $350 \mu \mathrm{m}$ sieve size and stored in desiccator.

\section{E. Characterisation of the magnetic bio composites}

Surface properties of the prepared samples were analysed by an atomic absorption spectrometer (AAS) (ICE 300 Series), Nicolet ISO10 Series FTIR Spectrometer and X-ray diffraction. The morphology of the optimised Moringa oleifera bionanocomposites was analysed using High-resolution transmission electron microscopy (HR-TEM, JEOL JEM-200, Japan). A Micrometrics Accelerated Surface Area Porosimetry (ASAP) 2000 nitrogen adsorption apparatus was used to characterise the Brunauer-Emmet-Teller (BET) surface area of the Moringa oleifera bionanocomposites.

\section{F. Swelling experiments.}

Swelling experiments were performed by weighing between $1.5 \mathrm{~g}$ of the de-oiled Moringa oleifera seeds with size ranges between $710 \mu \mathrm{m}-18 \mathrm{~mm}$.

\section{G. Batch adsorption experiments on the synthesised DMOS biocomposite (DMOS biocomp )}

All the batch adsorption experiments were performed by the ultrasound assisted method.10-25mls aliquots of the aqueous solutions containing approximately $95 \mathrm{ppm}$ of $\mathrm{Cr}(\mathrm{VI})$ ions with adsorbent dosage range of $0,002-0,05 \mathrm{mg} / 25 \mathrm{ml}$ at $\mathrm{pH}$ ranges of 4-6 and ultra sound time of $30 \mathrm{mins}$. The resultant solution was filtered and analysed by an AAS. The metal removal efficiency was calculated using the following equation:

$$
\% \mathrm{R}=\frac{\left(C_{0}-C_{t}\right)}{C_{0}}
$$

Where $\mathrm{C}_{0}(\mathrm{mg} / \mathrm{L})$ and $\mathrm{C}_{\mathrm{t}}(\mathrm{mg} / \mathrm{L})$ are the concentrations of the $\mathrm{Cr}$ (VI) ions at the initial and after time t, respectively. The adsorbed amount of the metal ions $\left(\mathrm{q}_{\mathrm{e}}(\mathrm{mg} / \mathrm{g})\right.$ was calculated using the following mass balance equation:

$$
q_{e}=\frac{\left(C_{0}-C_{e}\right) V}{W}
$$

Where $\mathrm{C}_{0}$ and $\mathrm{C}_{\mathrm{e}}(\mathrm{mg} / \mathrm{L})$ are the initial and equilibrium $\mathrm{Cr}$ (VI) ion concentrations in the aqueous solution, respectively. (L) is the volume of the solution and $\mathrm{W}(\mathrm{g})$ is the mass of the adsorbent used.

\section{H. Batch adsorption experiments for the synthesised de-oiled Moringa oleifera magnetite bionanocomposites.}

In order to investigate the adsorption of $\mathrm{Cr}$ (VI) on Moringa oleifera seeds functionalised magnetite bionanocomposites $\left(\mathrm{DMOSFeNP}_{\mathrm{H} 20}, \mathrm{DMOSFeNP}_{\text {salt }}\right.$, and $\left.\mathrm{DMOS}_{\text {biocomp }}\right)$ the adsorption method was performed under laboratory conditions at standard room temperature and pressure. Adsorption studies were done by preparing different concentration of the $\mathrm{Cr}$ (VI) solutions, which was achieved by dilution of the Cr (VI) stock solution at room temperature. Fixed amounts of bionanocomposites $(0.02 \mathrm{~g})$ were added to $50 \mathrm{ml}$ solutions containing different initial concentration of $\mathrm{Cr}$ (VI) ions. The $\mathrm{pH}$ of the resultant mixture was adjusted between 4-5 before being transferred to an orbital shaker for $2 \mathrm{hrs}$ at $1200 \mathrm{rpm}$. The resultant mixture was filtered through a Whatman number 42 filter and the supernatant liquid was collected in a $50 \mathrm{ml}$ volumetric flask for analysis. The concentration of the $\mathrm{Cr}$ (VI) ions was analysed using a Spectrophotometer 300. Before the adsorption experiments, calibration curve for $\mathrm{Cr}$ (VI) was run to analyse the $\mathrm{Cr}$ (VI) concentration in the analyte. The uptake of the $\mathrm{Cr}$ (VI) by the bionanocomposite particles, $\left(\mathrm{DMOSFeNP}_{\mathrm{H} 20}, \mathrm{DMOSFeNP}_{\text {salt }}\right.$, and $\left.\mathrm{DMOS}_{\text {biocomp }}\right)$ were calculated using equation (4).

$$
\mathrm{q}_{\mathrm{e}}(\mathrm{mg} / \mathrm{g})=\frac{\left(C_{i}-C_{e}\right) V(m l s)}{1000 \times m(g)}
$$

Where $C_{i}$ is the initial metal ion concentration $(\mathrm{mg} / \mathrm{g})$ and $\mathrm{C}_{\mathrm{e}}$ is the equilibrium or final concentration of the $\mathrm{Cr}$ (VI) ions at the end of the adsorption period.

\section{RESULTS AND DisCUSSIONS}

A. Characterisation of the de-oiled Moringa oleifera bionanocomposites: Point of zero charge

Adsorption of metal ions in solution depends on the solution $\mathrm{pH}$ as it affects the metal solubility constants and the surface charge. The solution $\mathrm{pH}$ determines the degree of dissociation of the functional groups on the surface of the adsorbent and metal solubility. The point of zero charge is the $\mathrm{pH}$ at which the surface of your adsorbent is neutral. Below this value, the surface is positively charged vice versa. The point of zero charge for de-oiled Moringa oleifera is between $4.0-6 \mathrm{p} \mathrm{H}$ range as shown in Fig. 1. The surface of the bionanocomposite was expected to be positive within this $\mathrm{pH}$ range. Adsorption experiments were carried out within this $\mathrm{pH}$ range for all the three bionanocomposites. 


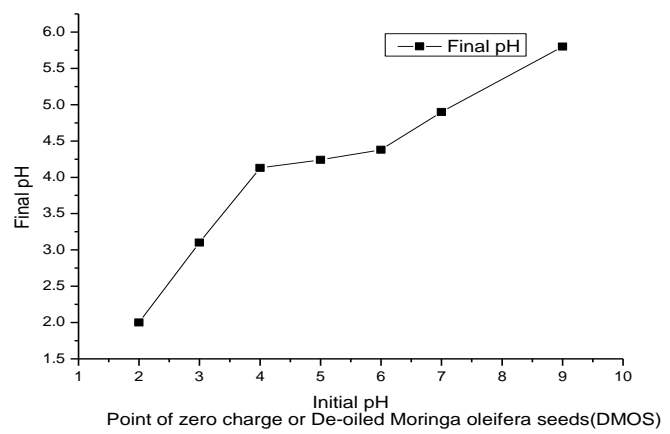

Fig 1: Point of zero charge for de-oiled Moringa oleifera seeds (DMOS)

\section{B. Pore structure analysis of the bionanocomposites.}

The highest average swelling ratio of the de-oiled Moringa oleifera seed was between $300-400 \mu \mathrm{m}$ sizes on the wet basis and was lowest on dry basis as shown in Fig. 2. The rate of swelling was determined by many physicochemical factors such as porosity and types of porous structure. The most optimum size for the maximum water intake by De-oiled Moringa oleifera seeds occurs between 300-400um. Therefore, for all the experiments, the sieve size range of 300-400um was used for the

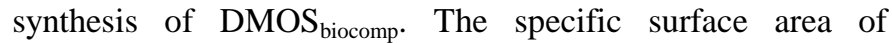
$\mathrm{DMOSFeNP}_{\mathrm{H} 20}, \mathrm{DMOSFeNP}_{\text {salt }}$, and $\mathrm{DMOS}_{\text {biocomp }}$ were 50.6, 38.8 and $50.6 \mathrm{~m}^{2} / \mathrm{g}$ respectively (Table 1.0 ). The specific surface area for DMOSFeNP $\mathrm{H} 20$ and $\mathrm{DMOS}_{\text {biocomp }}$ were found to be similar compared to DMOSFeNP $\mathrm{Dalt}_{\text {s. This difference could be as }}$ a result of coating with organic layer from Moringa oleifera saline extract on the bionanocomposite. Based on the surface area differences, the salt-coated composite was expected to have the least adsorption capacity towards the $\mathrm{Cr}$ (VI) ions in solution.

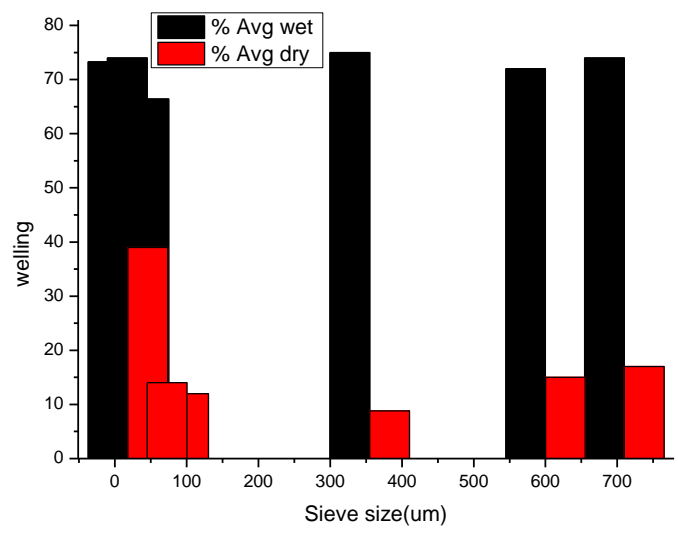

Fig. 2.Average \% swelling of DMOS in water.

TABLE I: SURFACE PROPERTIES OF DE-OILED MORINGA OLEIFERA SEEDS BIONANOCOMPOSITES.

\begin{tabular}{|l|l|l|l|}
\hline Properties & DMOSFeNP $_{\text {salt }}$ & DMOSFeNP $_{\mathrm{H} 20}$ & DMOS $_{\text {biocomp }}$ \\
\hline $\mathrm{S}_{\mathrm{BET}}\left(\mathrm{m}^{2} / \mathrm{g}\right)$ & $38.7811 \mathrm{~m}^{2} / \mathrm{g}$ & $50.6026 \mathrm{~m}^{2} / \mathrm{g}$ & $50.5960 \mathrm{~m}^{2} / \mathrm{g}$ \\
\hline $\begin{array}{l}\text { Pore volume } \\
\left(\mathrm{V}_{\mathrm{t}}\right)\left(\mathrm{cm}^{3} / \mathrm{g}\right)\end{array}$ & $0.5124 \mathrm{~cm}^{3} / \mathrm{g}$ & $1.2598 \mathrm{~m}^{3} / \mathrm{g}$ & $0.0837 \mathrm{~m}^{3} / \mathrm{g}$ \\
\hline Pore size & $52.85 \mathrm{~nm}$ & $99.59 \mathrm{~nm}$ & $6.619 \mathrm{~nm}$ \\
\hline
\end{tabular}

C. Crystalline and amorphous phases of the De-oiled Moringa oleifera seeds (DMOS

The crystalline and amorphous phases of the De-oiled Moringa oleifera seeds (DMOS), magnetic DMOS biocomp, $_{\text {, }}$ DMOSFeN $_{\text {Psalt }}$ and DMOSFeNP $\mathrm{H}_{\mathrm{H} 20}$ were characterised by XRD and the results are shown in Fig 3. DMOS characteristic peaks at around $2 \theta$ of $45^{\circ}$ which corresponds to magnetite. No peaks observed on the DMOS analysis expect for one peak at $2 \theta$ of $25^{\circ}$ due to the cellulose (II) crystalline form of the material. The width of this peak may be caused by the presence organic substances such as lignin and hemicellulose. The average crystalline sizes estimated by Williams Hall method were $17 \mathrm{~nm}, 69,21 \mathrm{~nm}$ and 90 , 97 for magnetite, $\mathrm{DMOSFeN}_{\text {Psalt }}$ and DMOSFeNP $\mathrm{H}_{\mathrm{H} 20}$ respectively. The increase in particles is caused by functionalization of the magnetite particles with soluble proteins from the two extracts. The XRD patterns described in literature by [6] indicate the presence of intense peaks at $2 \theta$ at $30.1^{\circ}, 35.4^{\circ}, 42.9^{\circ}, 57.5^{\circ}$ and $67.7^{\circ}$ representing the following diffraction patterns of magnetite with cubic spinel crystalline structure. The presence of intense peaks $35.82^{\circ}$ and $43.67^{\circ}$ representing diffraction patterns 417 and 495 for DMOSFeNPsalt show that magnetite produced is not pure. The same could be observed for DMOSFeNP $\mathrm{H}_{20}$ which showed peaks at $30.7^{\circ}$ and $35.74^{\circ}$ representing diffraction pattern 428 and 187 respectively.
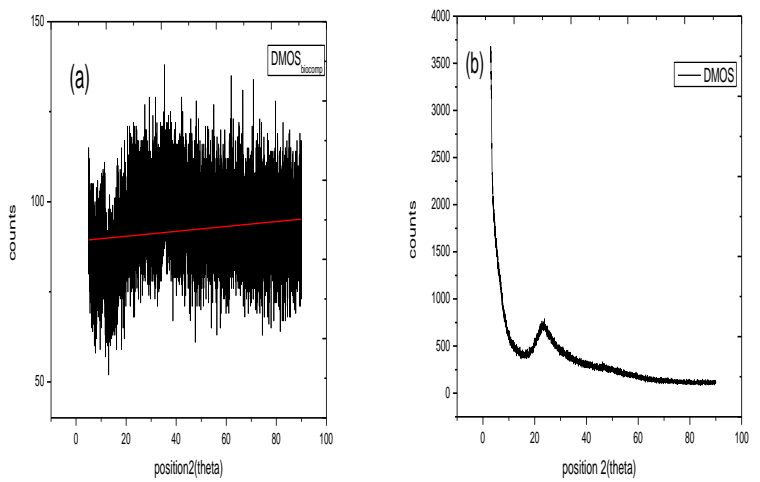

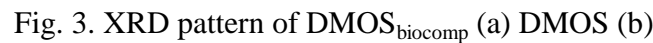

\section{SEM/EDAX analysis of the bionanocomposites}

The morphologies of the biocomposites were characterised by SEM/EDS. Untreated Moringa oleifera seed surfaces are rough, shiny and heterogeneous with rough structures on the surface Fig 4.0 (a), which suggests a potential for $\mathrm{Cr}(\mathrm{VI})$ adsorption. This surface appearance suggests the absence of dipole forces which prevents agglomeration and hence a well dispersed surface structure. Surface appearance for the functionalized $\mathrm{DMOS}_{\text {biocomp }}$ was different from the untreated Moringa oleifera seed powder. The DMOS with large clusters due to the stronger magnetic dipole-dipole forces of the $\mathrm{Fe}_{3} \mathrm{O}_{4}$ particles. The EDS results for the magnetite bionanocomposite show that $90 \%$ of the composition is $\mathrm{Fe}-\mathrm{O}$ see Fig 4.0 (b). The morphologies of DMOSFeNP $\mathrm{D}_{20}$ and DMOSFeNP $_{\text {salt }}$ were characterised using Scanning Electron Microscope (SEM) Surface images for Moringa oleifera water-soluble and salt soluble crude extracts modified 
magnetite nano particles are shown in Fig.4.0(c, d).The results show that in (c), the magnetite nanoparticles surface area was reduced by the presence of chloride precipitates on the surface of the magnetite particles.SEM image of the water modified magnetite nanoparticles in Fig 3,(d) show a large surface area of the magnetite nanoparticles exposed. This phenomenon leads to the conclusion that, surface structure, size distribution and extend of agglomeration are controlled by the type of Moringa seed extracts composition.EDX spectrum for DMOSFeNP $\mathrm{H}_{20}$ show that the weight $\%$ of $\mathrm{Fe}$ and $\mathrm{O}$ is higher than DMOSFeNP $_{\text {salt. }}$ The results show that in (d) the bionanocomposite particles were highly agglomerated while in (c) were well dispersed respectively. The agglomeration on the former particles can be attributed to stronger magnetic dipole-dipole moments and hence formed large clusters.
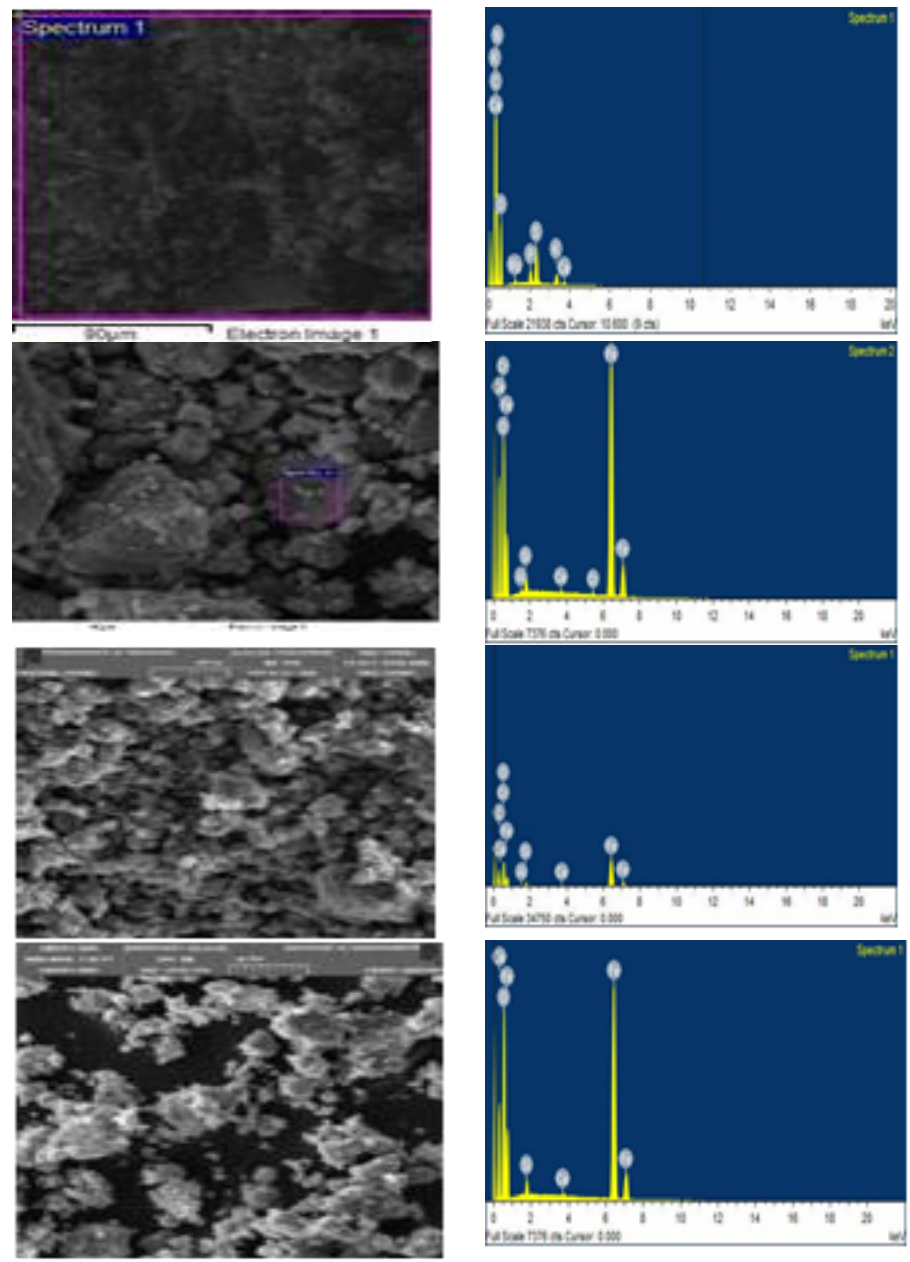

Fig 4. SEM/EDX images of the untreated DMOS (a), DMOS (b), DMOSFeNP salt $_{\text {(c) }}$, and DMOSFeNP $\mathrm{H}_{20}(\mathrm{~d})$

The presence of sodium chloride on the later disturbed the nuclear growth process, resulting in smaller well-dispersed clusters. The EDS/EDX results in Fig 4.0 indicate that 95\% of the material is magnetite

\section{E. FTIR results on unloaded bio nano composites.}

Infrared spectra was performed to identify the presence of functional groups on DMOSFeNP salt, $\mathrm{DMOSFeNP}_{\mathrm{H} 20}$ and Magnetite. Fig 5.0 shows the various functional groups in the bionanocomposites. For DMOSFeNP salt a band at $1067 \mathrm{~cm}^{-1}$ is assigned to stretching aromatic groups and the band at $1453 \mathrm{~cm}^{-1}$ and $1531 \mathrm{~cm}^{-1}$ shows the carboxylic group and amine groups respectively. These bands are due to protein and fatty acids found in the Moringa oleifera seeds [7]. The peaks at $1736 \mathrm{~cm}^{-1}$ and $1647 \mathrm{~cm}^{-1}$ indicate the presence of $\mathrm{C}=\mathrm{O}$ ester and $\mathrm{C}=\mathrm{NH}_{2}$ amides groups in the DMOSFeNP salt and DMOSFeNP $\mathrm{H}_{20}$ respectively. For DMOS a band at $3271 \mathrm{~cm}^{-1}$ is assigned to the $\mathrm{O}-\mathrm{H}$ stretching vibrations. A band at $791 \mathrm{~cm}^{-1}$ is attributed to $\mathrm{N}-\mathrm{H}$ bond of the amide groups. For DMOSFeNP salt and DMOSFeNP ${ }_{\text {н20 }}$ the $1651 \mathrm{~cm}-1$ and $1745 \mathrm{~cm}^{-1}$ are assigned to $\mathrm{C}=\mathrm{NH}_{2}$ amide group and $\mathrm{C}=\mathrm{O}$ ester groups respectively. Normally there is a shift on the functional groups because the functional groups on the bionanocomposites are interacting with magnetite causing less transmittance on the coated magnetite [8].The involvement of the complex protein polymers from the seed extracts in the formation, stabilization and surface functionalization of the synthesised magnetite nanoparticles can ascertained as we observe a sharp pick shifts at $791 \mathrm{~cm}^{-1}$. When the precursor solution $\left(\mathrm{FeCl}_{3}\right)$ is heated in an inert atmosphere. The magnetite formation starts by rapid precipitation of $\mathrm{Fe}(\mathrm{OH})^{+}$in water and if the concentration of dissolved oxygen is low in water and $\mathrm{pH}$ high slow oxidation takes place, and the dehydroxylation occurs prior to oxidation, so that the intermediate transfer to crystalline magnetite. The $\mathrm{Fe}(\mathrm{OH})^{+}$is oxidised to form an intermediate complex $\left[\mathrm{Fe}(\mathrm{OH})_{3}\right]^{+3}$ which reacts with another $\mathrm{Fe}(\mathrm{OH})^{+}$to form $\mathrm{Fe}_{3} \mathrm{O}(\mathrm{OH})_{4}{ }^{2+}$, which has the same ratio of $\mathrm{Fe}^{2+/} \mathrm{Fe}^{3+}$ of magnetite. The protein compounds in the Moringa seed extracts forms chelating compounds with complex ion species in solution thereby capping the surface of the nanoparticles. There is a general shift in the bands due to samples being in different media. The transmittance weakens between $500-1500 \mathrm{~cm}^{-}{ }^{1}$ due to the interaction of the seed extracts with the magnetite nanoparticles. More results are explained further by use of the Raman spectra Fig. 6 .

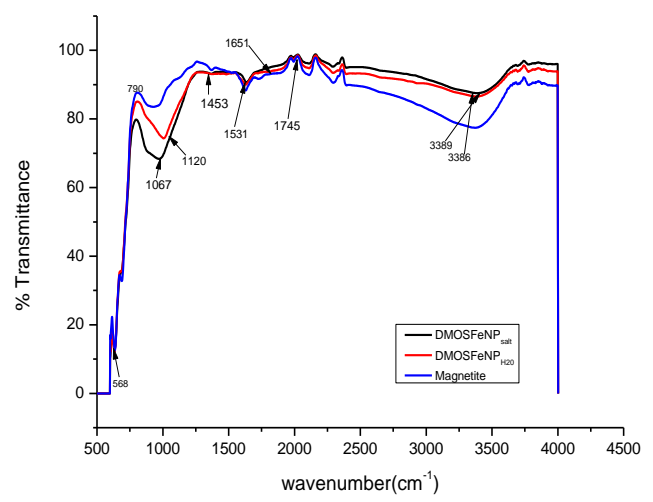

Fig 5. FTIR results for $\mathrm{DMOS}_{\text {salt }}$, DMOS $\mathrm{H}_{20}$ and Magnetite

\section{F. FTIR results of $\mathrm{Cr}$ (VI) loaded magnetite} bionanocomposites.

For the investigation of the removal mechanism of $\mathrm{Cr}$ (VI) ions, the FTIR spectra for the un-modified magnetite bionanocomposite particles before and after $\mathrm{Cr}$ (VI) loading were compared. The spectra for the modified magnetite bionanocomposite particles are not the same after $\mathrm{Cr}$ (VI) adsorption as shown in Fig 5.0 and 6.0 The characteristics peaks at $1398 \mathrm{~cm}^{-1}$ and $1638 \mathrm{~cm}^{-1}$ may be assigned to $\mathrm{C}-\mathrm{O}$ and $-\mathrm{R}-\mathrm{NH}_{2}$ 
groups of proteins and enzymes in the Moringa seed extract. This shows that the magnetic nanoparticles were modified with oleic acid and the carboxylic acid from the monomer was retained. [9]. The infrared band at $1410 \mathrm{~cm}-1$ can be assigned to bending vibrations of the $\mathrm{O}-\mathrm{H}$ bond, which validates the presence of phenolic derivatives such as lignin in the extracts. Amino acid-chromium (VI) interactions can be deduced on the basis of their FTIR results before and after $\mathrm{Cr}$ (VI) loading on the magnetite bionanocomposites. Fig 5.0 shows the FTIR spectra of untreated DMOSFeNP salt. $_{\text {. }}$ showing the presence of $\mathrm{O}-\mathrm{H}$ stretching vibrations and the contribution for the vibrations of the $\mathrm{N}-\mathrm{H}$ groups at $3389.15 \mathrm{~cm}^{-1}$ and $1629.66 \mathrm{~cm}^{-1}$ due to $\mathrm{C}=\mathrm{NH}_{2}$ amide groups vibrations. The shift of the amine/amide groups in unloaded composite $\left[3389.15 \mathrm{~cm}^{-1}\right)$ to $\left[3379.13 \mathrm{~cm}^{-1}\right]$ in $\mathrm{Cr}(\mathrm{VI})$ treated $\mathrm{DMOSFeNP}_{\text {salt }}$ confirms ionic interaction between amide groups of the amino acids with the $\mathrm{Cr}(\mathrm{VI})$ ions as shown in Fig 6.0.below. A shift on the untreated composite $\left[1629.66 \mathrm{~cm}^{-1}\right)$ to $\left[1631.92 \mathrm{~cm}^{-1}\right)$ indicate strong ionic interaction of the amine groups with the $\mathrm{Cr}$ (VI) ions. The same shift showing strong interaction between $\mathrm{Cr}(\mathrm{VI})$ ions with DMOSFeNP $_{\mathrm{H} 20}$ can observed on the untreated bionanocomposites at $\left[3384.20 \mathrm{~cm}^{-1}\right)$ to treated bionanocomposites at $\left[3386 \mathrm{~cm}^{-1}\right]$ showing strong interactions of the $\mathrm{Cr}(\mathrm{VI})$ with the amine groups. The FTIR spectrum of magnetite nano particles show intense bands at $568 \mathrm{~cm}^{-1}$. Therefore, it can be concluded that during the metal ion removal process, there is a chemical reaction-taking place between the adsorbent and adsorbate and it is not physio sorption process. Same observations can be noted for magnetite before loading at $\left[1630.23 \mathrm{~cm}^{-1}\right]$ and after loading with $\mathrm{Cr}$ (VI) ions at $\left[1635.74 \mathrm{~cm}^{-1}\right]$. Formation of iron nano particles in the DMOSFeNP $_{\text {salt }}$ and DMOSFeNP $\mathrm{H} 20_{2}$ can be confirmed by the bands at $567 \mathrm{~cm}^{-1}$ in Fig 7.0 as shown in Raman spectra.

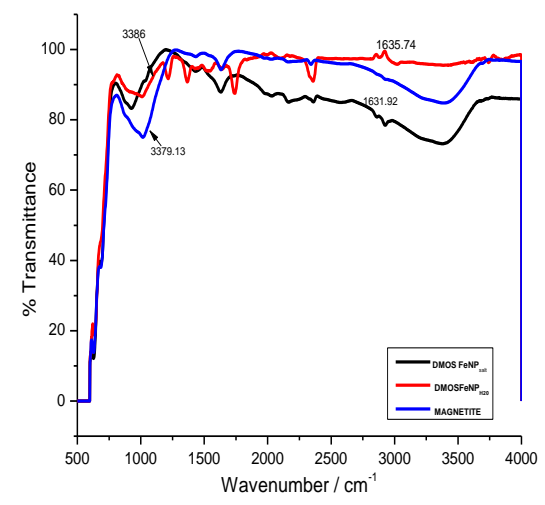

Fig 6. FTIR spectra of Cr (VI) loaded DMOSFeNP salt, $_{\text {, }}$ DMOSFeNP $_{\mathrm{H} 20}$ and Magnetite

\section{G. Raman analysis}

Raman spectra was performed to identify the nature of chemical bonding and crystallographic orientation of samples on the surface of the DMOSFeNP ${ }_{\text {н2 }}$ and DMOSFeNP $\mathrm{Dalt}_{\text {alt }}$ Fig 7.0 shows the two spectra of the bionanocomposites. Series of Raman spectra collected at gradual increase of laser power started for show hematite bands at about $300-400 \mathrm{rcm}^{-1}$. From Fig 7.0 the Raman scattering power of hematite is less than that of magnetite in the DMOSFeNP ${ }_{\text {H20 }}$ as compared to

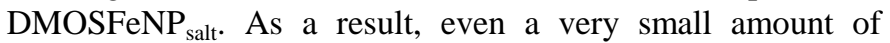
hematite causes the presence of spurious peaks in the Raman

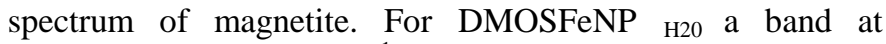
$588,610,630$ and $790 \mathrm{~cm}^{-1}$ confirms the presence of $\mathrm{Fe}-\mathrm{O}$ vibrations. The same can be observed for the DMOSFeNP salt on Fig 7.0, (b). Meanwhile, the Raman spectra for DMOSFeNP ${ }_{\text {H20 }}$ Fig 6.0 also displayed peaks at $3520 \mathrm{~cm}^{-1}$ for stretching for $\mathrm{O}-\mathrm{H}$,at $1616 \mathrm{~cm}^{-1}$ for the $\mathrm{C}=\mathrm{C}$ and $1049 \mathrm{~cm}^{-1}$ for C-O-C adsorption peaks. The presence of $\mathrm{O}-\mathrm{H}$ in plane bend can be confirmed at band $1356 \mathrm{~cm}^{-1}$ for the DMOSFeNP $\mathrm{H}_{\mathrm{H} 0}$ showing the presence of primary and secondary alcohols in the seed extract. A band at $1410 \mathrm{~cm}-1$ for the DMOSFeNPH20 is attributed to bending $\mathrm{O}-\mathrm{H}$ groups, which validates the presence of phenolic derivatives in the water extract. The absence of such peaks on DMOSFeNP $_{\text {salt }}$ shows that the water extract is a better media in growing magnetite nanoparticles than salt. Similar results were obtained by Luo et al, 2016 for the degradation of Orange II using grape leaf aqueous extract to synthesis of bimetallic Fe/Pd nanoparticles [10] .
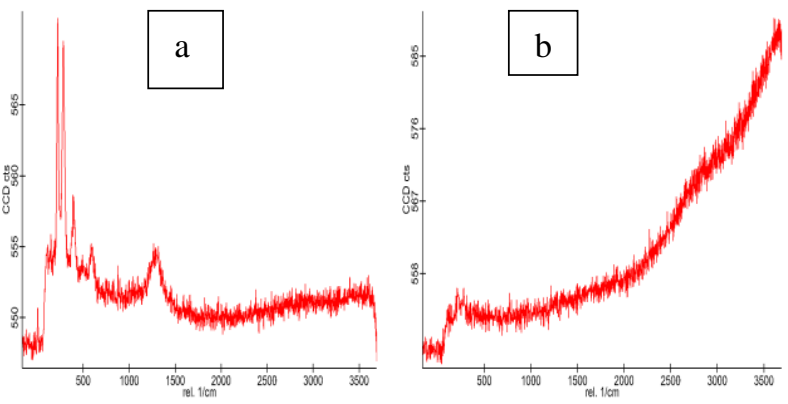

Fig. 7: Raman spectra DMOSFeNP ${ }_{\mathrm{H} 20}(\mathrm{a})$, and $\mathrm{DMOSFeNP}_{\text {salt }}(\mathrm{b})$

\section{H. HRTEM analysis}

Knowing surface morphology of the nanoparticles is of paramount importance since their surface to volume ratio is a principle feature in nanotechnology. To characterise further the microstructure of the synthesised magnetite nanoparticles, were done using High-resolution TEM analysis (HRTEM). Fig 8.0 below shows perfect lattice fringes in selected regions of individual particles, which confirms the formation of crystalline magnetite nanoparticle in both samples. The HRTEM image for $\mathrm{DMOSFeNP}_{\mathrm{H} 20}$ are spherical in shape, and well dispersed compared to DMOSFeNP salt $_{\text {. Yadav et al. reported similar }}$ finding by describing the spherical shape of the iron nano particles prepared from Aloe vara. [11]. This is due to the organic layer from Moringa seed salt extracts covering the surface of the nano particles. EDX spectrum shows the elemental composition of the synthesized bionanocomposites. The $\%$ of $\mathrm{Fe}$ and $\mathrm{O}$ is high in DMOSFeNP ${ }_{\text {salt }}$ compared to the $\mathrm{DMOSFeNP}_{\mathrm{H} 20}$. Their stoichiometric ratio does not resemble the pure magnetite nanoparticles and hence the spectrum is consistent with X-ray patterns of the sample showing phase impurity. Presence of extra peaks in the spectrum indicate that this is not recommended method for synthesizing pure magnetite (supplementary notes) The presence of chloride peaks on DMOSFeNP ${ }_{\text {salt }}$ confirms the surface morphology, size distribution and extend of agglomeration are controlled by the 
type of seed extract.

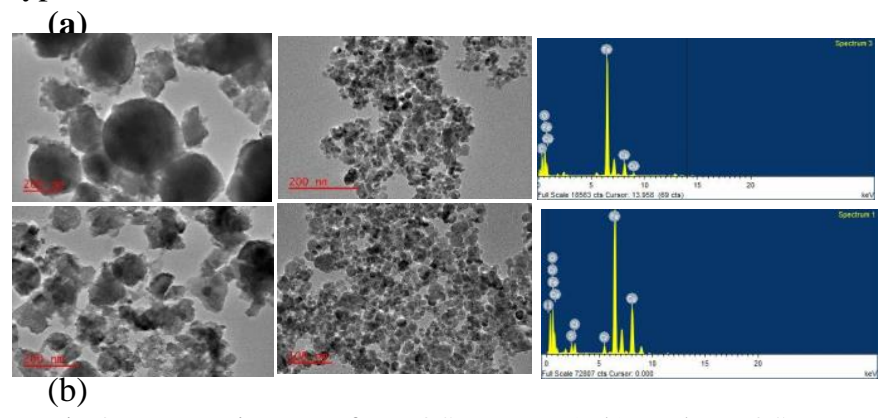

Fig.8 HRTEM images of DMOSFeNP $\mathrm{H}_{20}(\mathrm{a}-\mathrm{b})$, and $\mathrm{DMOSFeNP}_{\text {salt }}$

\section{ADSORPTION STUDIES}

The adsorption of the prepared $\mathrm{Cr}(\mathrm{VI})$ in aqueous solution was performed using the three bionanocomposites and the results were compared to untreated Moringa oleifera seeds. In order to obtain the maximum recovery for the determination of $\mathrm{Cr}$ (VI), the mass of the composite, $\mathrm{pH}$, extraction time and initial metal ion concentration was investigated, and the results are shown below.

\section{J. Effect of $p H$}

The $\mathrm{pH}$ is the most important parameter to consider in solid-phase extraction process as it affects the surface charges and metal speciation chemistry of the bio-sorbent as shown in Fig.9.0 below. The solution $\mathrm{pH}$ affects the degree of dissociation of the carboxyl and hydroxyl functional groups of the adsorbent and the solubility of the $\mathrm{Cr}$ (VI) on magnetite bionanocomposites. The effect of $\mathrm{pH}$ on $\mathrm{Cr}$ (VI) was investigated between 1 to 10 and the results are shown in Fig 9.0 below. The maximum extraction efficiency was obtained at $\mathrm{pH}$ range 6-8 which coincide with the point of zero charge for the de-oiled Moringa oleifera seeds. At that $\mathrm{p} \mathrm{H}$ the surface charge on the Moringa oleifera bionanocomposites is positive which attracts the negatively charged $\mathrm{Cr}$ (VI) ions which predominantly exists as $\mathrm{CrO}_{4}^{-}$in abundancy in acidic media.Cr (VI) sorption decreased as the solution $\mathrm{pH}$ increased to 8 because as the $\mathrm{p} \mathrm{H}$ increases the magnetite groups and other functional groups like the carboxylic, ethers and hydroxyl in the Moringa extracts deprotonate creating a negative surface charge density which reduces the uptake of $\mathrm{Cr}$ (VI) from the solution [12].The fluctuation on the DMOSFeNP salt $_{\text {at higher }} \mathrm{pH}$ can be caused by erosion or degradation of the organic layer at higher $\mathrm{pH}$ exposing positive surface which attracts more $\mathrm{Cr}(\mathrm{VI})$

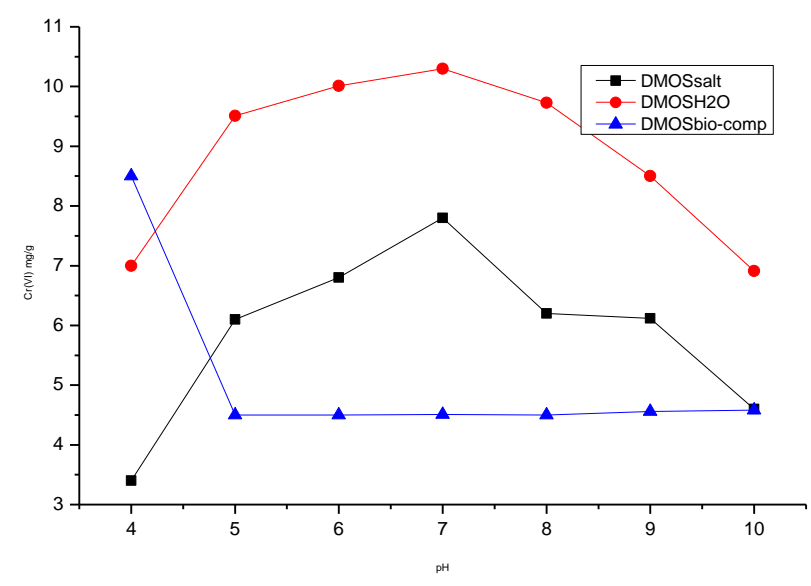

Fig.9 Effect of solution p H on Cr (VI) adsorption

\section{K. Effect of adsorbent dosage}

The recoveries of $\mathrm{Cr}$ (VI) decreased with increase in dosage quantities for all the three-magnetite bionanocomposites. The adsorption of $\mathrm{Cr}$ (VI) was highest at the initial stages of the experiment and decreased gradually as the bio-sorbent dosage increase from 0.01 to $0.07 \mathrm{~g}$ see Fig 10.0 below This means that the number of ions bound to the adsorbent and the free ions in solution remain constant even if we increase the biosorbent dosages. This indicates poor biomass utilisation efficiency at higher dosages. The results can be explained as a result of partial aggregation, which occurs at high biomass concentrations giving rise to decreased active sites [13].This effect was also reported by [14] for the sago waste for the adsorption of lead and copper .

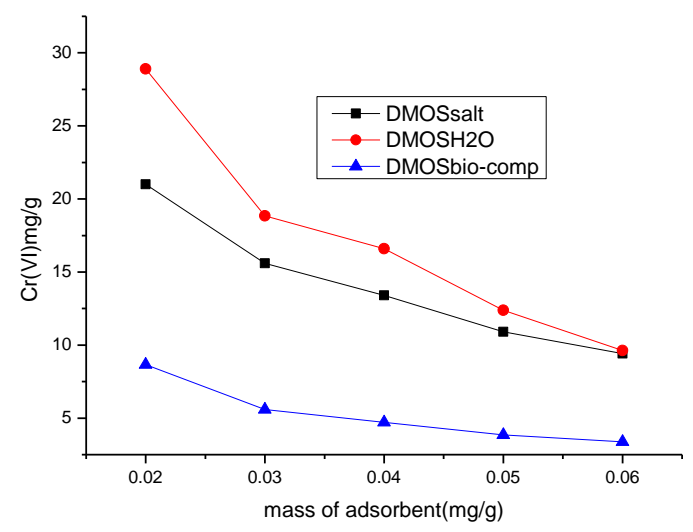

Fig.10 Effect of adsorbent dosage on $\mathrm{Cr}$ (VI) adsorption.

\section{Effect of time}

The equilibrium times affect the quantity of pollutant adsorbed over a period of time and the adsorption time was optimised for the recovery of the $\mathrm{Cr}(\mathrm{VI})$ ions in solution. The time intervals for the determination of the amount of $\mathrm{Cr}$ (VI) adsorbed was kept constant (30mins) for 180 mins as shown in 
Fig 11.0 below. The results show that maximum adsorption took place in the first $60 \mathrm{mins}$ contact time with $\mathrm{DMOSFeNP}_{\mathrm{H} 20}$ having the highest adsorption capacity followed by

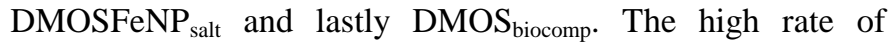
adsorption is due to high surface area and pore volume of DMOSFeNP $_{\mathrm{H} 20}$ compared to the other two bionanocomposites. It dropped gradually after 1 hour and increases steadily until it reaches equilibrium after $150 \mathrm{mins}$. This could be due to metal ion adsorption desorption mechanisms over that period or ligand formation followed by rapid $\mathrm{Cr}$ (VI) adsorption as time progresses. Therefore, $150 \mathrm{mins}$ is the optimum adsorption time for chromate (VI) ions. Degradation of the organic layer formed on surface of the bionanocomposites can cause fluctuations in $\mathrm{Cr}$ (VI) uptake at higher $\mathrm{pH}$. The $\mathrm{DMOSFeNP}_{\mathrm{H} 20}$ was less affected as compared to DMOS biocomp $_{\text {and DMOSFeNP }}$ salt.

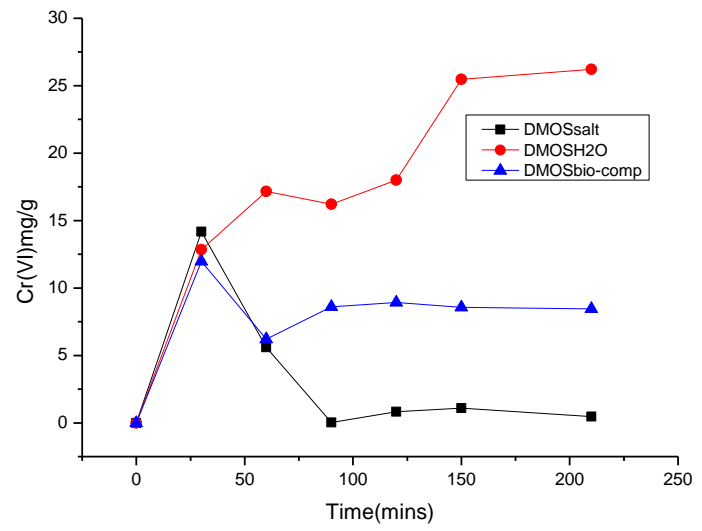

Fig.11 Effect of time on Cr (VI) adsorption.

M. Effect of initial concentration of Moringa oleifera bio-composite:

The results of the experiments in Fig 12.0 below show minimum metal removal efficiency with lower initial concentration of the $\mathrm{Cr}$ (VI) ions in solution. As the initial concentration of $\mathrm{Cr}$ (VI) increases to 20ppm, the amount of $\mathrm{Cr}$ (VI) ions adsorbed increases steadily, reaches $10 \mathrm{mg} / \mathrm{l}$ for the DMOSFeNP $_{\mathrm{H} 20}$, and is very low for the other two-magnetite bionanocomposites. Any further increase in the initial concentration of $\mathrm{Cr}$ (VI) from 20ppm resulted in the decrease in the adsorption capacity of $\mathrm{Cr}$ (VI) for $\mathrm{DMOS}_{\text {biocomp }}$ and DMOSFeNP $_{\text {salt }}$, while that of DMOSFeNP $\mathrm{H}_{20}$ increases. The decrease in adsorption can be attributed to the lower ratio of available sites for $\mathrm{Cr}$ (VI) adsorption at higher initial concentration of the $\mathrm{Cr}$ (VI) ions. Thus, at low initial concentrations, the removal efficiency is higher and vice versa. When the metal ion concentration increases the reaction sites dwindle but in this case for the Moringa oleifera magnetite bionanocomposites there seems to be a plentiful supply of these unoccupied sites which allows the adsorption of $\mathrm{Cr}$ (VI) to increase with the increase in the initial concentration of the $\mathrm{Cr}$ (VI) ions in solution for the DMOSFeNP ${ }_{\mathrm{H} 20}$. Any drop in adsorption means saturation of the active and an increase in adsorption illustrate availability of active sites for more intake of $\mathrm{Cr}(\mathrm{VI})$ ions.

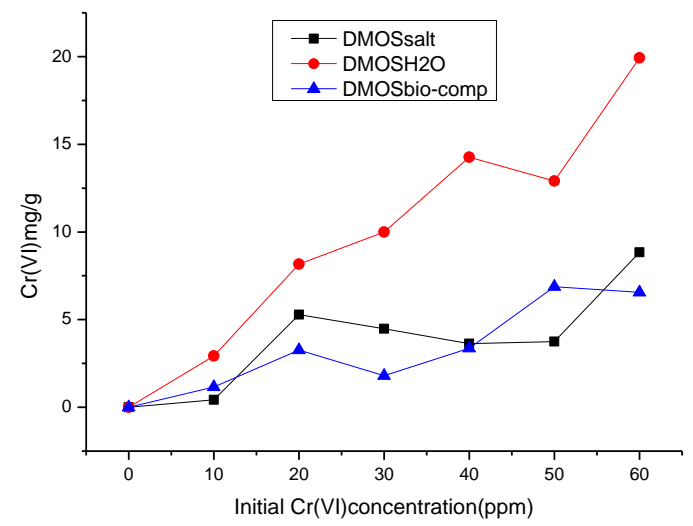

Fig.12 Effect of initial Cr (VI) concentration on Cr (VI) adsorption.

\section{N. Adsorption and kinetic models for Moringa oleifera} bionanocomposites:

The adsorption and kinetic are done to show nature of adsorption and the mechanisms of adsorption of the pollutant on the biosorbate respectively. A summary of results are shown on table 2.0 below:

TABLE II SUMMARY OF ADSORPTION AND KINETIC MODELS

\begin{tabular}{|l|c|l|l|r|}
\hline \multicolumn{1}{|c|}{ Bio sorbent } & $\mathbf{q}_{\max }(\mathbf{m g} / \mathbf{g})$ & $\begin{array}{l}\text { Adsorption } \\
\text { model }\end{array}$ & $\begin{array}{l}\text { Kinetic } \\
\text { model }\end{array}$ & $\mathbf{p H}$ \\
\hline $\begin{array}{l}\text { De-oiled Moringa } \\
\text { seeds }\end{array}$ & 3.19 & Langmuir & 2nd order & $5-7$ \\
\hline DMOS bio comp & 6.86 & Fraundlich & 2nd order & $4-5$ \\
\hline DMOSFeNP $_{\text {salt }}$ & 6.37 & Langmuir & 2nd order & $4-6$ \\
\hline DMOSFeNP $_{\mathrm{H} 2 \mathrm{O}}$ & 33.18 & Langmuir & 1st order & $4-6$ \\
\hline
\end{tabular}

\section{CONCLUSION}

This work represents a simple technique for synthesis of modified Moringa oleifera magnetite nano particles with an average particle size distribution of $15-100 \mathrm{~nm}$ by a simple precipitation method. BET analysis results showed that the surface area of the synthesised samples are between $25 \mathrm{~m}^{2} / \mathrm{g}-50 \mathrm{~m}^{2} / \mathrm{g}$ and the porous distribution determined by BJH method indicate all the prepared samples are mesoporous with pore size range of $2-50 \mathrm{~nm}$. It was discovered that the salt extract from the seeds tend to reduce the particle size of magnetite particles by $50 \%$ and decrease its surface area by $20 \%$ compared to the water extracts. The DMOSFeNP ${ }_{\mathrm{H} 20}$ showed a good removal efficiency of $33.18 \mathrm{mg} / \mathrm{g} \mathrm{Cr}(\mathrm{VI})$ ions $(80 \%)$ in solution by its well-dispersed functionalised Moringa oleifera magnetite nano particles as compared to Unfunctionalised DMOS, DMOS biocomp $_{\text {and DMOSFeNP }}$ salt. $3.19 \mathrm{mg} / \mathrm{g}, 6.86 \mathrm{mg} / \mathrm{g}$ 
and $6.37 \mathrm{mg} / \mathrm{g}$ respectively. The resulting adsorbent can easily be separated from the pollutant by magnetic separation. The adsorption models for $\mathrm{DMOS}_{\text {biocomp, }}$ DMOSFeNP $\mathrm{Dalt}_{\text {sat }}$ and $\mathrm{DMOSFeNP}_{\mathrm{H} 2 \mathrm{O}}$ followed Fraundlich, and Langmuir adsorption models respectively. These adsorption isotherm models indicates that the adsorption process occurs in a monolayer and multilayer heterogeneous surface respectively. The kinetic models for DMOS biocomp, and DMOSFeNP $_{\text {salt }}$ followed second order reaction kinetic however, DMOSFeNP ${ }_{\mathrm{H} 2 \mathrm{O}}$ followed first order kinetics The first order kinetics and second order kinetics shows the reaction of $\mathrm{Cr}$ (VI) on the magnetite bionanocomposites is physisorption and chemisorption respectively. This shows that adsorption of $\mathrm{Cr}(\mathrm{VI})$ takes place via surface exchange reaction mechanisms until all the sites are occupied. Therefore, Moringa seed extracts can be used to support magnetite bionanocomposites for $\mathrm{Cr}$ (VI) adsorption. Other potential future research is to synthesis a Moringa oleifera nano magnetic composite, which works on wider $\mathrm{pH}$ range.

\section{REFERENCES}

[1] A. Nisha, R. Pandey, "Heavy metal and health." Institute of Engineers. pp. 1-6, 1984.

[2] D. R.Bartlet, "Behaviour of chromium in soils," Environmental Quality Index., pp. 31-35, 1979. https://doi.org/10.2134/jeq1979.00472425000800010008x

[3] B. Voleski, "Removal of trivalent and hexavalent chromium by seaweed biosorbent." Environmental Science \& Technology, vol. 32, no. 18, pp. 2693-2698, 1998. https://doi.org/10.1021/es971073u

[4] T.A Kurniawan, G. Chan, W. Lo, "Comparisons of low-cost adsorbents for treating waste water laden with heavy metals," Total Environment, Vols. 2-3, no. 366, pp. 409-426, 2005. https://doi.org/10.1016/j.scitotenv.2005.10.001

[5] A.V. Luis, H.G. Thiago, A. Gasela, F. Raquel, "Aquatic toxicity of dyes before and after photon-Fenton treatment." Harzardous Materials, pp. 332-338, 2014. https://doi.org/10.1016/j.jhazmat.2014.05.047

[6] D. Abass, "Facile sono chemical synthesis of high moment magnetite nanocube," Nanoparticles, pp. 1354-1365, 2013.

[7] M. Pattanayk, P. Navak, Nano Science Technology, vol. 2, pp. 6-9, 2013.

[8] M.M.Kgatitsoe, "Synthesis of magnetic sorbents modified with Moringa Oleifera extracts for removal of organic pollutants," Wits University, johannesburg, 2018.

[9] K.Liu, J. Nasrallar, L. Chen, L. Huang, "Preparation of CNC-dispersed magnetic nanoparticles and their application in conductive paper," Carbohydrates Polymers, pp. 78-175, 2015. https://doi.org/10.1016/j.carbpol.2015.03.009

[10] F.Luo, D. Yang, M. Megharay, "One step green synthesis of bimetallic Fe/Pd nanoparticles used to degrade Orange (II)," Harzardous Material, no. 303, pp. 145-153, 2015. https://doi.org/10.1016/j.jhazmat.2015.10.034

[11] R.S. Yadav, J. Vilcakova, I. Kurikta, "Structural, magnetic, optical, di-electric, electrical and modulus spectroscopic," Physics and chemistry, no. 110, pp. 87-89, 2017. https://doi.org/10.1016/j.jpcs.2017.05.029

[12] M.Fazlzadeh , K.Rahmani, A.Zarei, "A novel green synthesis of zerovalent iron nano particles using three plant extracts and their efficient removal of $\mathrm{Cr}(\mathrm{VI})$ ions," Powder Technology, vol. 28, pp. 122-130, 2017. https://doi.org/10.1016/j.apt.2016.09.003

[13] N.M. Saifuddin, K. Palanisamy, "Removal of heavy metals from industrial wastewater using chitosan coated oil palm shell charcoal," Biotechnology, pp. 44-53, 2005.

[14] S.Y. Quek, D.A.G. Wise, C.F. Forster, "The use of Sago waste for the sorption of lead and copper." Water SA, no. 24, pp. 251-256, 1998. 